\title{
Another Perspective on Case Studies in Civil Engineering Design - The Gardiner Expressway
}

\author{
P. Berjis ${ }^{1}$ and D. K. Panesar ${ }^{2}$ \\ ${ }^{1}$ MASc Candidate, Department of Civil Engineering, University of Toronto \\ ${ }^{2}$ Assistant Professor, Department of Civil Engineering, University of Toronto \\ (d.panesar@utoronto.ca)
}

\begin{abstract}
Civil engineering education at graduate and undergraduate levels commonly draws on structural engineering case studies, such as the 1907 Quebec Bridge Collapse or the 1981 Hyatt Regency Collapse to illustrate the significance of technical engineering design decisions, and their implications. A study of the Gardiner Expressway in a senior level civil engineering design course is valuable for a variety of reasons and are discussed in the paper.

Construction of the Fredrick G. Gardiner Expressway, which acts as a main commuter route through Downtown Toronto, began in 1956 and was completed in 1965. Today, at over 50 years old, the expressway is experiencing traffic congestion, and visible degradation of structural materials, and consequently public safety may be compromised. This paper explores the history of the Gardiner Expressway and aspects of its design as it pertains to the current state of the aging infrastructure. There is a need for students to gain an understanding, exercise design skills and the design process in application to current, real world engineering design challenges such as aging structures and infrastructure.
\end{abstract}

\section{Introduction}

Civil engineering education traditionally draws on structural engineering case studies, such as the 1907 Quebec Bridge Collapse or the 1981 Hyatt Regency Collapse to illustrate the significance and implications of technical engineering design decisions [1][2]. This paper introduces the Gardiner Expressway as an engineering design study for a senior level civil engineering design course that is of interest for the following key reasons: i) The expressway is very real to civil engineering students at the University of Toronto since many of them are users of it. They have experienced the traffic congestion, and they have seen the material degradation.

ii) The study of the Gardiner Expressway requires an understanding of various fields of civil engineering including, structural design, transportation, engineering economics, and concrete material science.

iii) It is a dynamic project which has been undergoing construction (repair, replacement) and various studies (transportation studies, and environmental assessment) for decades. It is a well documented infrastructure project.

iv) It also illustrates the significance and cost associated with functional failure as opposed to a complete collapse failure which often leads to lives lost.

There is a need for students to gain an understanding of the complexities associated with aging civil engineering infrastructure, their maintenance, monitoring, evaluation, and the design of solutions. This is highlighted by the occurrence of current events such as the collapse of an overpass in Laval, Quebec on September 30, 2006. This resulted in the death of five people and caused serious injuries for six others [3]. Residents in the surrounding area and users of the overpass had expressed concern over the state of concrete degradation prior to its collapse [4].

Fortunately the aging Gardiner expressway has not resulted in such a serious event as in Montreal, but it is clear that attention to preliminary signs is necessary in order to prevent catastrophic failures. To date, it is reported that small pieces of concrete have spalled off the expressway structure and have fallen on the pathway underneath. On one occasion, concrete which weighed approximately $20 \mathrm{~kg}$ fell on a vehicle at York 
St [5]. No injuries resulted from this incident, but it clearly indicates the possibility of material failure which could result in fatality. In addition to the concern of loss of life, it should be noted that the City of Toronto, in one year, spent $\$ 80$ million of its $\$ 300$ million road repair budget on the Gardiner, and this number does not take into account the factors such as pollution, cost of delay and environmental damages [6].

In recent years, other jurisdictions around the world have investigated the reliability of their aging elevated transportation infrastructure. For example, structures that are relevant to the Gardiner expressway situation include: New York City (West Side Highway/Miller Highway); San Francisco (Embarcadero Freeway); Boston (Central Artery /Rose Kennedy Greenway); Milwaukee (Park East Corridor); and Barcelona, Spain (Ronda del Litoral) [7]. Research of similar projects, also refereed to as 'reference works of engineering' bore similarities specifically with respect to their experience with problems, managing design constraints, challenges, implementation of solutions, and social impacts. All of these considerations are a necessary part of the design process in order to effectively evaluate design alternatives.

Currently, a Gardiner Expressway Environmental Assessment and Integrated Urban Design Study is underway where four key alternatives are being considered to manage the structure: (i) do nothing and maintain the elevated expressway, (ii) improve the existing expressway which could include modification to its configuration and surrounding infrastructure, (iii) replace with a new expressway, and (iv) remove the elevated expressway with a lower capacity, lowerspeed roadway [7]. Irrespective of the alternative selected, the four key project goals developed by the City of Toronto's Official Plan and Central Waterfront Secondary Plan and with public and stakeholder input must be fulfilled. The four goals include: "revitalization of the waterfront to provide an adequate access to open space, landscape land and air; reconnect the city with the lake to make accessible routes to the waterfront, which involves breaking down physical and psychological barriers that exist; balance modes of travel including local and regional transportation systems, transit, cycling, and walking within the system; and achieve sustainability through commitments to green, healthy, and energy efficient development and employ sustainable design solutions that can improve environmental quality and biodiversity, and minimizes public health risks" [7].

A study of the expressway in its current state, in a senior level civil engineering design course captures several aspects of a challenging real world design project. Specifically, the following attributes lend themselves to having a strong potential as a design project for civil engineering students.

- Practical civil engineering aspects of the real-world project have significant importance to society.

- The topic is a broad civil engineering problem which would require structural, material, transportation, and environmental design and analysis and so consequently would be accompanied but various potential solutions.

- Research of reference works of engineering is necessary because it is a relatively unexplored area and the optimum solution is not obvious and is the topic of discussion/ debate. As a result, there is an opportunity to incorporate emerging technologies to create effective and innovative design proposals.

- For final year engineering students, the conceptual design work and the preliminary detailed design can be based on the knowledge base that has been gained in their previous years of the undergraduate program.

- Initial design work related to the expressway has good potential to be illustrated through the usage of drawings and/or models.

This study provides a brief background of the expressway and its designer. The paper will then provide some examples related to the existing condition of the concrete and aspects of concrete repair design and implications on transportation delay and the corresponding costs. In addition to the visible degradation of the structural material, the expressway is also experiencing traffic congestion and the coupled effect has the greater possibility of compromising public safety. Figure 1 illustrates the various aspects of design which contribute to the design of the aging elevated expressway.

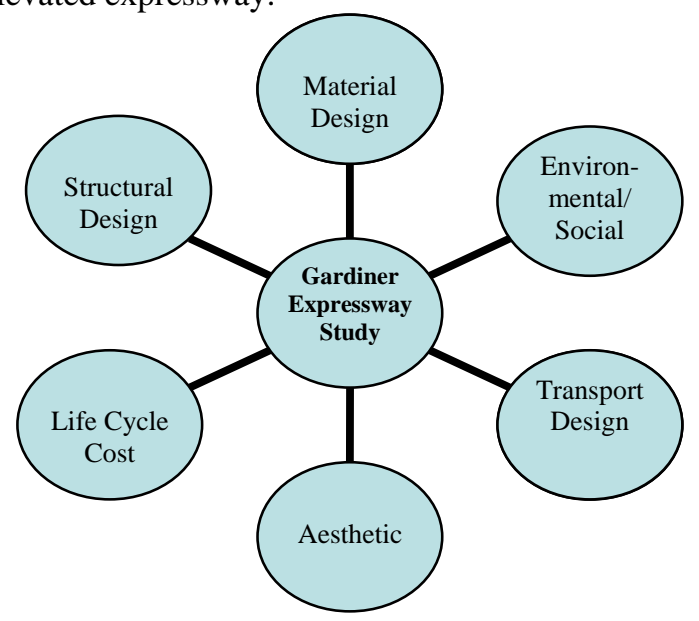

Figure 1: Aspects relevant to the study of the Gardiner Expressway 


\section{Gardiner Expressway Case Study}

\subsection{Background}

Mr. Fredrick G. Gardiner was a graduate of University of Toronto's political science program and later on Osgoode Hall School of Law, and was a cofounder and the first chairman of Metro Toronto's government [8]. He was highly accomplished and his contributions to the city of Toronto were many, including the Gardiner Expressway, expansion of the TTC, the Subway Network system and an exceptional welfare system. He made a billion dollar commitment in 1953 to the city's infrastructure program over a ten year period, a value of 172 billion dollar in today's dollars, an unprecedented commitment [9].

Mr. Gardiner had his dream of making Toronto a Metropolitan phenomenon like New York. In this dream he ignored the human factor associated with the design of this structure from a systems perspective [8]. The lack of environmental and social considerations in the Gardiner design resulted in the creation a physical and mental segregation between social, cultural and urban roots of the waterfront and Toronto itself [10]. This is illustrated through decisions made by the designers and planners of the Gardiner which resulted in destruction of a large residential area as well as a number of historic sites which were on its path [11][6][10]. The construction of the Gardiner involved destruction of 170 homes in the South Parkdale Community, Sunny Side Amusement park, and the arch marking the entrance to the Exhibition place [6]. Fort York was the only historical site along Gardiner's path that was preserved.

The Fredrick G. Gardiner Expressway, known as Gardiner Expressway to the locals runs over 20 kilometres and it connects downtown Toronto to its Western Suburbs [12]. At the time of construction, the downtown waterfront was a heavy industrial area and so the expressway was designed to provide the city with goods and materials. The planning of the expressway started in 1943, however it was under the newly formed government of Metro Toronto that the construction process started in 1955. The price tag for this project was $\$ 110$ million (equivalent to $\$ 700$ million in 2006) and it took 11 years to complete.

Currently, the expressway acts as a main commuter route through Downtown Toronto. Figures 2 and 3 show the Toronto Waterfront before and after existence of the Gardiner Expressway, respectively. It runs over 20 kilometres from the foot of Highway 427 and the Queen Elizabeth Way in the West to the Don Valley Parkway in the East.

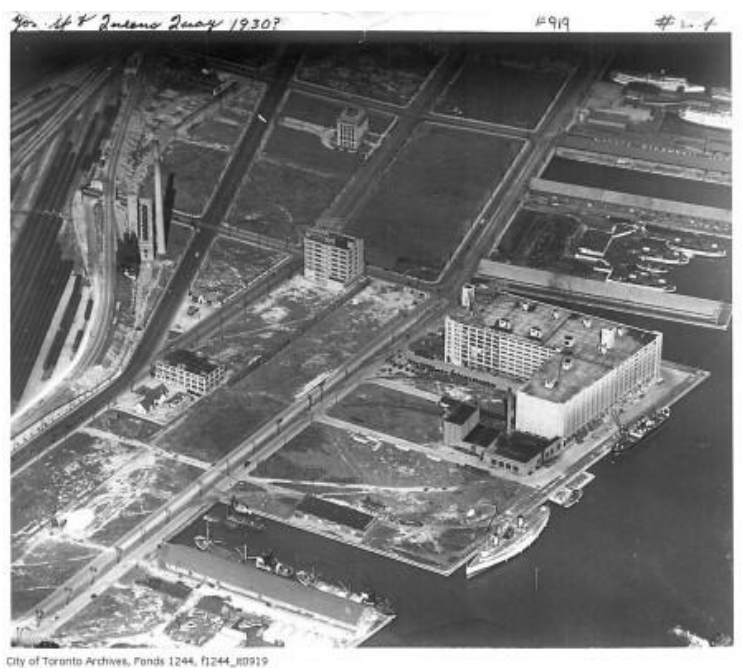

Figure 2: Queens Quay (1930)- Waterfront Toronto before Gardiner [13]

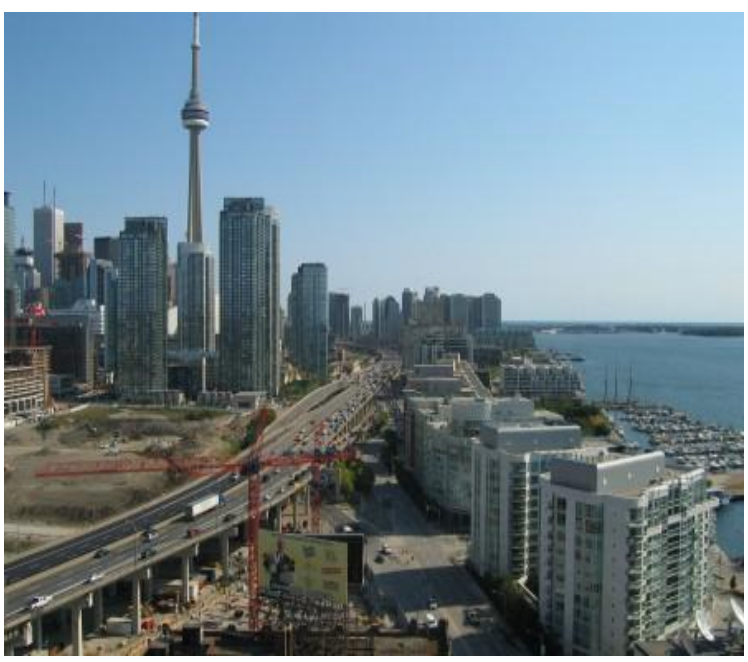

Figure 3: Waterfront Toronto after Gardiner [13]

\subsection{Structural and Material Design}

The deck structure is a simply supported and semicontinuous precast prestressed and post tensioned concrete box girder. Most girders are prestressed girders, $0.76 \mathrm{~m}, 0.91-1.22 \mathrm{~m}$ wide deep with spans varying from 18 to $22 \mathrm{~m}$. Some girders that are of longer span lengths are post tensioned with seven 12 $\mathrm{mm}$ diameter strands in each grouted duct. The posttensioned box girders are $1.14 \mathrm{~m}$ deep and span 27-30 $\mathrm{m}$. The girders are covered by a poured-in-place concrete topping, waterproofing and asphalt or a composite reinforced concrete slab with asphalt and waterproofing.

One key reason as to why the study of the Gardiner is relevant to University of Toronto civil engineering students is because many of them are users of it. They 
have experienced the traffic congestion, and they have seen the material degradation. The close proximity of the expressway to the downtown Toronto campus lends itself to be a very feasible site for students to conduct a structural condition assessment. The design processes related to the expressway first consists of identifying the problem which involves preliminary steps such as conducting a site visit and performing a condition assessment, preliminary diagnosis of the structure, planning a non destructive and destructive testing program based on the observed symptoms in order to identify the root cause(s) of the damage. To assist in this process, students can gain a realistic perspective of aging infrastructure by conducting an assignment which necessitates a field study.

Today, clear observation of the Gardiner Expressway reveals concrete degradation, evidence of water leakage, and varying degrees of conditions of previously rehabilitated material. The Expressway has undergone repair construction since 1982. Some of the visible repair schemes that have been applied include: shotcrete, replaced girders, and carbon fibre reinforcing polymer strengthening strips. In addition, minor repairs such as patching waterproofing, paving and expansion joint repair and replacement have also been carried out.

A closer look at the material degradation reveals that the concrete, reinforcing steel and the prestressing tendons have undergone varying degrees of degradation. A visual inspection of the expressway from underside Lake Shore Blvd. and Fort York reveals the following forms of material degradation and is also shown in Figure 4 and 5.

- delamination due to the corrosion of reinforcing and prestressing/post tensioning steel (localized to large areas of soffit and exposed web of exterior girders)

- light to severe corrosion of exposed reinforcing steel and prestressing steel mainly in exterior girders, girder ends, strands adjacent to the bottom slab drainage holes and areas adjacent to the mainline ramp interface

- areas of concrete spalling

- longitudinal cracks on the underside of the girders

- horizontal narrow cracks on the exposed webs of the exterior girders

- delamination of previously shotcrete patched areas

- concrete delamination on the face of pier caps

- efflorescence at various girder to girder interfaces, including locations where the girders previously patched with shotcrete

- corrosion of transverse post tensioning tendons causing delamination and spalling on the side face of exterior girders

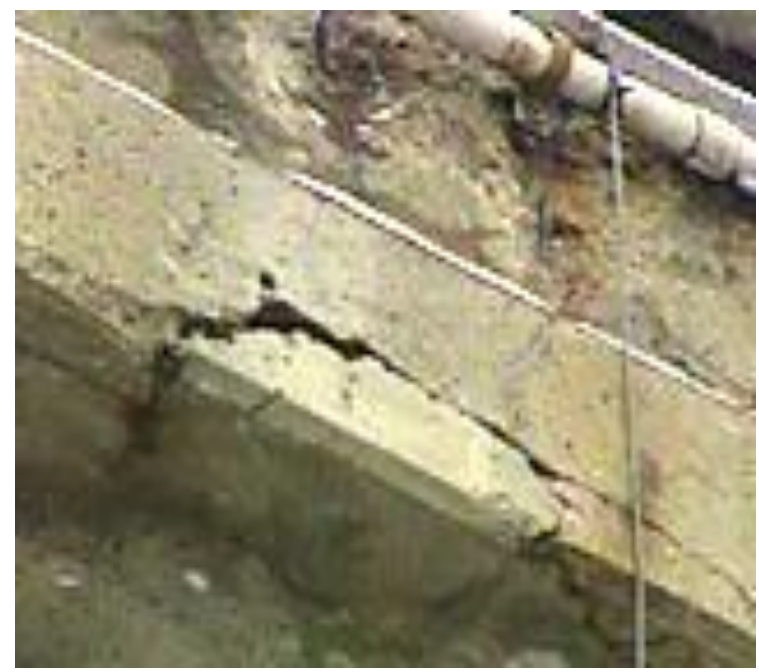

Figure 4: Concrete Cracks and Spalling [5]

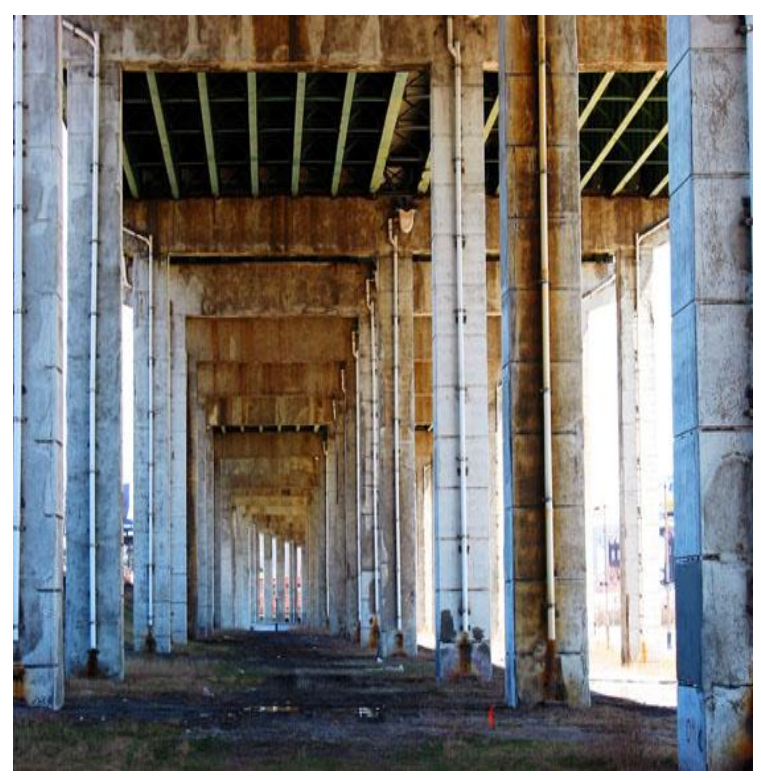

Figure 5: Underside of Fort York [5]

The damaged concrete and the corroded reinforcing steel and prestressing strands have undergone a functional failure which is the inability of the design to satisfy the intended objectives and requirements. Timely inspection, maintenance and repair programs are necessary for aging infrastructure in order to prevent the occurrence of failures that could potentially pose as a huge threat for the travellers.

The cost of maintenance and material repair is estimated at $\$ 10$ to $\$ 12$ million per year, which does not account for costs related to traffic delay due to partial or full lane closures [6]. To administrate these maintenance procedures, various partial or full closures need to be taken into account since there are no shoulder lanes available [7]. Section 2.3 focuses on the 
implication of repair construction on traffic disruption and lane closures. However, it should be noted that additional costs are also incurred due to adverse effects of fuel consumption, air quality and traffic safety and additional costs to municipalities through slowing commerce [14].

\subsection{Transportation Design}

This paper addresses two aspects of transportation perspective of the Gardiner expressway. Firstly, the issue of traffic congestion and secondly, the cost associated with partial or full lane closures necessary for maintenance and repair procedures.

At the time when Gardiner was built it was anticipated that the daily use will be around 40,000 to 60,000 vehicles, however since then this number has grown to 120,000 and even up to 200,000 at some locations [15][7]. Coupled with the greater volume of traffic flow, the length of several of the ramps has also added to the traffic congestion. The design of the ramps has resulted in a very short merging distance and the weaving distance between the on and off ramp is limited and cannot satisfy the continuous flow of traffic. Also since there are no shoulders, any breakdown can cause a full or partial closure [10]. The traffic congestion created by this process is a growing source of frustration for Municipalities and their citizens, by increasing travel times, slowing commerce, and creating safety hazards. Specifically, incapability of Gardiner to satisfy the demand has led to congestion to become over $80 \%$ of the capacity from 7:30 to $19: 30$ hours [10] at Dufferin. Gardiner's ability to effectively meet the traffic demands has severely decreased over the years. This is illustrated by the average speed of $43.4 \mathrm{~km} / \mathrm{hr}$ during the morning peak hour and further reduced to $36.5 \mathrm{~km} / \mathrm{hr}$ during the evening peak hour [10].

Inspection, major repair and maintenance operations have cost implications related to traffic delay due to lane closures and also pose safety risks to workers and travellers, and are a source of annoyance for users and the occupants of neighbouring facilities [16]. This study focuses on the analysis of the user delay costs which is calculated based on the Ontario Ministry of Transportation (MTO) Geometric Design Standards for Ontario Highways Chapter-B 2002, through incorporating its nine step procedure. MTO estimates value of an average traveller at $\$ 10$ /hour for cars and \$50/hour for trucks [17]. Based on MTO methodology, equations 1 to 5 will be used to evaluate the impact of lane closures throughout the day [18][17]. These calculations are based on the capacity, car and truck volume demand and the demand data collected by Water Front Revitalization Corporation in
2004. Since it is reported that the time that the demand is over $80 \%$ of the capacity is between $7: 30$ to $19: 30$ hours [10] this analysis is applied to computation of user delay costs is for weekdays, between the hours of 7:30 and 19:30 where the traffic is consistently above $80 \%$ capacity. This study also considers the number of simultaneous lane closures to range from one to three.

Adjustment Factor for Heavy Vehicles

$$
f h v=1 /\left\{1+P_{t}\left(E_{r}-1\right)\right\}
$$

Conversion to Cars

$$
V_{\text {arrival }}=\left(V_{\text {trucks }} / f h v\right)+V_{\text {cars }}
$$

Queue

Hourly Delay

$$
Q_{t}=V_{\text {arrival }^{-} \text {Capacity }_{w z}}+Q_{t+1}
$$

Delay Cost

$$
\begin{gathered}
\text { Delay Cost }=(\text { Total Delay })\left\{(\% \text { Truck })\left(\text { Cost }_{t}\right)+\right. \\
\left.(1-\% \text { Truck })\left(\text { Cost }_{\text {cars }}\right)\right\}
\end{gathered}
$$

Where,

Capacity $_{w z}=$ throughput $(\mathrm{vph}=$ vehicles per hour)

$P_{t}=$ proportion of trucks to cars $(20 \%)$

$E_{r}=$ car equivalent for trucks (2)

$F h v=$ adjustment factor for heavy vehicles (0.833)

$V_{\text {arrival }}=$ arrival rate in terms of cars (vph)

$V_{\text {trucks }}=$ volume of trucks (vph)

$V_{\text {cars }}=$ volume of cars (vph)

$Q_{t}=$ queue for thour (vehicle)

$Q_{t+1}=$ queue for previous hour (vehicle, assumed 0)

Hourly Delay = vehicle delay $(\mathrm{vph})$

$\operatorname{Cost}_{t}=$ delay cost for trucks $(\$ / \mathrm{hr})$

Cost $_{\text {cars }}=$ delay cost for passenger car $(\$ / \mathrm{hr})$

Figure 6 reveals the cost of delay presented in dollars per hour as a function of time during the day and based on the number of lanes closed. As expected the data shows that as the number of lanes close increase the cost of closure significantly increases. The cost of one lane closure ranges from $\$ 7,000$ to $\$ 15,000$ and the costs increase by a factor of approximately $200 \%$ for the scenario where two lanes are closed $(\$ 25,000-\$ 33,000)$. For full closure, the cost of delay is calculated to be approximately $500 \%$ that of the cost of delay for the scenario of a single lane closure. The cost of delay for the case of three lanes closed simultaneously ranges from $\$ 43,000$ to $\$ 51,000$. 


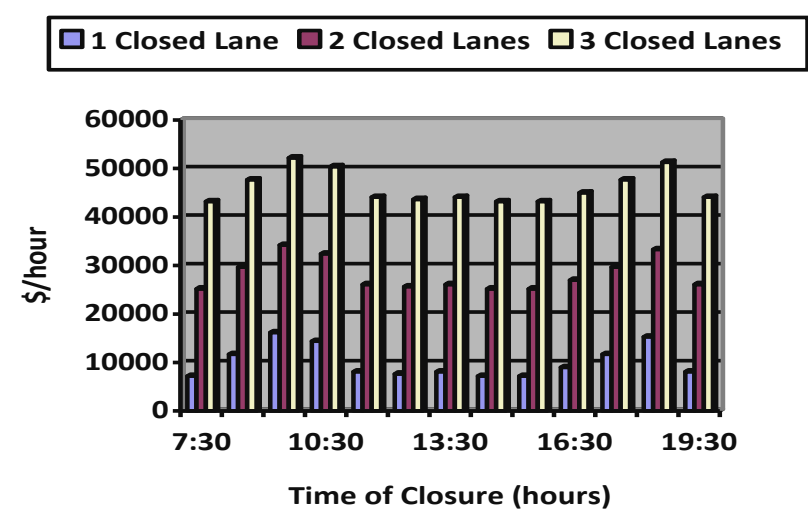

Figure 6: Cost of Delay

\section{Summary and Concluding Remarks}

Typically, discussions of engineering failures tend to be associated with structural or material failures that have ended in tragedy. This is certainly the case for Hyatt Regency collapse and the Quebec Bridge failure, where lack of competence of the engineers and ineffective communication resulted in tragic events and lives lost. However, many times engineering failures do not necessarily end in such catastrophe; as is the case with Gardiner Expressway, many engineering failures often fail in a sense that they fail to satisfy the functions which they were originally intended for.

The Gardiner expressway is relevant to the key fields of civil engineering (transportation, material, structure, environmental), and its implications should be explored in senior year engineering courses. This type of design project will help engineering students to develop more holistic perspective and to exercise design skills in context with real world civil engineering challenges, criteria and constraints associated with the evaluation, repair, and management of aging structures and infrastructure.

\section{References}

[1] W.M.K Roddis "Structural Failures and Engineering Ethics" J. Struct. Engrg. Volume 119, Issue 5, pp. 1539-1555 (May 1993).
[2] R.D. Marshall, E.O. Pfrang, E.V. Leyendecker, and K.A. Woodward, "Investigation of the Kansas City Hyatt Regency walkways collapse” Nat. Bureau of Standards, Washington, May 1982.

[3] B. Marotte, J. Magder, "Quebec launches inquiry into overpass collapse", Globe and Mail Update with Canadian Press, Montreal, October 02, 2006.

[4] The Associated Press, "Canada overpass collapse kills five", Denver Post, Denver, October 01, 2006.

[5] A. Mihailovich, "Concerete Falls From Gardiner Expressway Again” CTV News, Toronto, 2007.

[6] C. Li "Transforming the Gardiner Expressway: A Vision for Personal Rapid Transit in 2015" University of Waterloo, Dept. Of Architecture, Waterloo, 2006.

[7] Toronto Waterfront Revitalization Corporation. (2004). Economic Impact of Gardiner Expressway Alteration (Draft ed.) [Brochure]. Toronto, On.: Deloitte.

[8] The Empire Club Foundation, "The Empire Club of Canada Speeches 1961-1962" The Empire Club Foundation, Toronto, 1962.

[9] R. Fulford, Accidental City: The Transformation of Toronto. Macfarlane Walter \& Ross, Toronto, 199.

[10] Gardiner/Lake Shore Corridor Study Team Technical Briefing: Gardiner/Lakeshore corridor Toronto Water Revitalization Corporation, Toronto, July 15, 2004.

[11] M. Blackett, "The Future of the Gardiner Expressway". Spacing Toronto, Toronto, May 30, 2008.

[12] M. Piattelli, Fact Sheet: FG Gardiner Expressway Waterfront Toronto, Toronto, On. 2006.

[13] HOK Toronto "That Thing in the Middle" $H O K$, Toronto, 2009, available at: http://hoklife.com/2009/06/19/that-thing-in-themiddle/\#more-9313

[14[ A. Al-Kaisy, E. Kerestes, "Evaluation of the Effectiveness of Single-Lane Two-Way Traffic Control at Maintenance \& Reconstruction Zones" Transportation Research Board Annual Meeting . Washington, 2005.

[15] J. Royson, "A lesser dream, but a possible one" The Star, Toronto, May 31, 2008.

[16] P. DeCorla-Souza, "Estimating Costs, Benefits and Revenues from Regionwide Freeway Congestion Pricing" Transportation Research Board Annual Meeting, Washington, 2008.

[17] Ministry of Transportation of Ontario "Chapter B Update. In Geometric Design Standards for Ontario Highways" Ministry of Transportation, Ottawa, 2002.

[18] I. Shaikh, "Freeway Workzone Capacity and Associated Economic Concepts. MASc thesis" Dept. of Civil Engineering, University of Waterloo, Waterloo, 2002. 